\title{
Interaction of HLA and immunoglobulin antigens in Type 1 (insulin-dependent) diabetes
}

\author{
L. L. Field ${ }^{1}$, C. E. Anderson ${ }^{2}$, K. Neiswanger ${ }^{3}$, S. E. Hodge ${ }^{4}$, M. A. Spence ${ }^{3,4}$ and J. I. Rotter ${ }^{5}$ \\ ${ }^{1}$ Division of Medical Genetics, Department of Pediatrics, and Department of Community Health Sciences, University of Calgary, and Alberta \\ Children's Hospital, Calgary, Alberta, Canada; ${ }^{2}$ Division of Clinical Genetics, Department of Pediatrics, University of California at Irvine, \\ Orange; Departments of ${ }^{3}$ Psychiatry and ${ }^{4}$ Biomathematics, University of California School of Medicine, Los Angeles, and ${ }^{5}$ Division of Medical \\ Genetics, Departments of Medicine and Pediatrics, UCLA School of Medicine, Harbor-UCLA Medical Center, Torrance, California, USA
}

Summary. We analyzed 88 unrelated subjects with Type 1 (insulin-dependent) diabetes and 64 sibling controls (maximum one per diabetic) for associations between immunoglobulin allotype antigens (GM and KM) and Type 1 diabetes. None were found. However, we did find interactions between GM, HLA-DR, and Type 1 diabetes (significant or of borderline significance after considering the effect of multiple tests): possession of $\operatorname{Glm}(2)$ appeared to increase susceptibility to diabetes in individuals who had HLA-DR3 but not HLA-DR4, while possession of G3m(5) appeared to increase susceptibility in individuals who had HLA-DR4 but not HLA-DR3. These results suggest that genetic predisposition to Type 1 diabetes is partially determined by alleles at the GM locus (or a locus in linkage disequilibrium with GM) interacting with alleles at the HLA-DR locus (or a locus in linkage disequilibrium with HLA-DR).

Key words: Type 1 diabetes, immunoglobulin allotypes, HLA, GM, KM, INV, disease marker, genetic linkage.
Type 1 (insulin-dependent) diabetes is thought to be a disease resulting in most cases from autoimmune destruction of the host's own pancreatic $\beta$ cells, possibly virally initiated [1]. If Type 1 diabetes represents an abnormal immune system reaction to environmental agents, then immune response genes may be involved in its pathogenesis. In mice there are immune response genes linked to immunoglobulin heavy chain structural genes [2] and to the major histocompatibility complex [3]. There is some evidence for analogous sets of immune response genes in man, i.e. linked to the GM and HLA loci [4-6]. There is also some evidence in man for immune response genes linked to the immunoglobulin light chain locus, KM $[7,8]$. The evidence is indirect and consists of findings of associations between immune responsiveness and GM, HLA, or KM marker antigens; one possible cause of these associations is linkage with disequilibrium between immune response loci and marker loci. Since the known associations of HLA-DR3 and HLA-DR4 antigens with susceptibility to Type 1 diabetes [9] may reflect linkage with disequilibrium between the HLA-DR locus and such immune response loci, it is logical to search also for associations between susceptibility to Type 1 diabetes and the GM and KM immunoglobulin antigens. We report here the results of such a search.

\section{Subjects and methods}

\section{Subjects}

Serum samples were available from 88 Caucasoid, Californian families with one or more Type 1 diabetic members. These families are part of an investigation [10-13] into the genetics of susceptibility to Type 1 diabetes. Affected subjects were defined as having had acute onset of insulin dependence before 40 years of age [10]. From each of the 88 families, we selected the oldest affected person and the oldest unaffected sibling (available in 64 of the families) as a control. We felt it was important to use siblings as controls in order that controls be precisely matched to patients in terms of ethnic background. If controls had been matched only as "Caucasoid" (more precise matching is difficult) and if, for genetic or environmental reasons, Type 1 diabetes were not uniformly distributed among the genetically diverse ethnic groups forming the Caucasoid population of California, spurious genetic differences between patients and controls would have resulted. Our study design eliminated Type 1 error due to such ethnic mismatching. Unfortunately, sibling controls are also very conservative, since a diabetic has a greater probability of sharing a marker allele with a normal sibling than with a random individual from the general population. Thus, any real difference between patients and controls would be more difficult to detect. We therefore decided that any difference with a $p$ value $<0.1$ should be considered of potential interest.

\section{Genetic marker typing}

All individuals were typed for three GM antigens and one KM antigen: $\mathrm{G} 1 \mathrm{~m}(1), \mathrm{G} 1 \mathrm{~m}(2), \mathrm{G} 3 \mathrm{~m}(5)$ and $\mathrm{Km}(1)$. The prefixes "G1m" and "G3m" indicate that GM antigens 1, 2, and 5 occur on gamma-1 and gamma-3 heavy chains. The loci encoding these two heavy chain types are very closely linked; alleles at the loci are inherited together in combinations called haplotypes. Due to strong linkage disequilibrium, only three haplotypes arc common in Caucasoids of European origin. These three haplotypes are: $G m^{1}\left(G m^{1,17 ; 21,26,27}\right.$ when typed for a wider array of antigens), $\mathrm{Gm}^{1,2}\left(G m^{1,2,17 ; 21,26,27}\right)$ and $\mathrm{Gm}^{5}$ $\left(\mathrm{Gm}^{3} ; 5,10,11,13,14,26,27\right)$. Antigens determined by the haplotype are indicated in the superscript, with heavy chain prefixes removed and instead a semi-colon used to separate G1m and G3m antigens). The $\mathrm{Km}(1)$ antigen is controlled by the $K m^{1,2}$ allele, which in Caucasoids is much less common than the $\mathrm{Km}^{3}$ allele. The GM and KM antigens were typed using a standard agglutination-inhibition technique [14] adapted for microtitre plates. The anti-allotype antisera used were Mor, Tyl, Wat, and Rut, and the anti-D coats were Pet and Hun. Samples which contained agglutinating antibodies were heat-inactivated at $65^{\circ} \mathrm{C}$ for $10 \mathrm{~min}$ and re-typed. 
HLA-DR antigens had been previously determined in the laboratory of Dr. P.I.Terasaki using a standard microlymphocytotoxicity procedure [15]. Fourteen of the 88 diabetic patients and 12 of the 64 sibling control subjects were not DR-typed; they were therefore not included in analyses involving HLA-DR.

\section{Analysis}

Two sets of analyses were performed: (1) two-way analyses to search for simple association of genetic marker antigens (HLA-DR, GM, KM) with susceptibility to Type 1 diabetes, (2) three-way analyses to search for interactions between two markers and susceptibility to diabetes. During analysis, the data for each variable were dichotomized (as described below) to attempt to satisfy the requirement that all cells have expected cell counts of at least 1.0. This requirement is probably conservative, since Kotze [16] suggested that in multiway analyses up to $20 \%$ of cells may have expected cell counts $<1.0$. All two-way analyses, and all three-way analyses involving HLA by KM and HLA by GM, satisfied our more conservative requirement. However, threeway analyses, involving $\mathrm{KM}$ by GM, and four-way analyses did not meet the requirement in many cases and are therefore not considered in this study.

In the first set of analyses, KM was dichotomized by presence or absence of $\mathrm{Km}(1)$. $\mathrm{GM}$ was dichotomized by $\mathrm{G} 1 \mathrm{~m}$ (1) or, in separate analyses, by $\mathrm{G} 1 \mathrm{~m}(2)$ or $\mathrm{G} 3 \mathrm{~m}(5)$. HLA data were grouped into four phenotypic classes which, with regard to susceptibility to Type 1 diabetes, are biologically distinct: $\mathrm{DR} 3 / \mathrm{X}, \mathrm{DR} 3 / \mathrm{DR} 4, \mathrm{DR} 4 / \mathrm{X}$, and $\mathrm{X} /$ $X$, where 'DR3/X' means positive for DR3 but not DR4, 'DR4/ $X$ ' means positive for $D R 4$ but not $D R 3$, and ' $X / X$ ' means negative for both DR3 and DR4. To examine the known associations of HLA with Type 1 diabetes, these four phenotypic classes were then dichotomized by presence or absence of DR3 and/or DR4. In the second set of analyses, KM and GM were dichotomized as in the first set. However, to search for possible interactions between HLA and immunoglobulin markers, we wished to maintain the four distinct HLA classes. This was not possible because the DRX/X class contained only four diabetic and seven control subjects. Since it could not meaningfully be merged with any other class, it was dropped from the interaction analyses.

Log-linear models were fitted to the multi-way cross-classified data using the computer program P4F from the 1981 BMDP software package [17]. We assessed the significance of an association or interaction effect by the $\mathrm{G}^{2}$ test statistic, which compared the goodness-of-fit of the model with and without that effect. Models were fitted to the table of data collapsed over variables not involved in the effect - i.e., we performed a test of marginal association [18]. For such goodnessof-fit comparisons, $\mathrm{G}^{2}$ is asymptotically distributed as $\chi^{2}$ with degrees of freedom equal to (I-1) (J-1) for association effects and (I-1) (J-1) (K-1) for interaction effects, where $\mathrm{I}, \mathrm{J}, \mathrm{K}$, are the number of classes for each of the variables involved in the effect [17]. We assessed the need to correct for multiple tests using the method described in the Appendix.

Interactions found to be significant were further investigated by examining the association of the immunoglobulin marker with disease within HLA categories. The significance of these $2 \times 2$ associations was assessed by the $\chi^{2}$ test statistic (results for Fisher's exact test are also given in one case where total sample size was 28 , even though the $\chi^{2}$ test is probably more appropriate [19]).

\section{Results}

\section{Association of genetic markers with disease}

The raw data for the 88 diabetic and 64 sibling control subjects are presented in Table 1 . The known associations of HLA-DR antigens with Type 1 diabetes were seen in the sample of 74 diabetic and 52 sibling control subjects who were DR-typed: compared with control subjects, the diabetic patients had a higher frequency of
DR3, although the difference was not significant $(51 \%$ versus $40 \% ; \mathrm{G}^{2}=1.48$, d.f. $=1, p=0.22$ ) and a higher frequency of DR4 $\left(77 \%\right.$ versus $58 \% ; \mathrm{G}^{2}=5.30$, d.f. $=1$, $p=0.02$ ). (These results demonstrated the conservativeness of the sibling controls, since the frequencies of the DR3 and DR4 antigens in the American Caucasoid general population are about $23 \%$ and $28 \%$ [20]). Furthermore, the increase of DR3 and DR4 in diabetic patients was primarily due to their much higher frequency of DR3/DR4 heterozygotes $(34 \%$ versus $12 \%$; $\mathrm{G}^{2}=8.75$, d.f. $=1, p=0.003$ ).

There was no association of KM with Type 1 diabetes: $17 \%$ of 88 diabetic and $17 \%$ of 64 control subjects were positive for $\mathrm{Km}(1)\left(\mathrm{G}^{2}=0.00\right.$, d.f. $\left.=1, p=0.98\right)$. $\mathrm{GM}$, dichotomized by $\mathrm{G} 1 \mathrm{~m}(1)$, did not show association with Type 1 diabetes: $50 \%$ of diabetic patients were positive for $\mathrm{G} 1 \mathrm{~m}(1)$ compared with $47 \%$ of controls $\left(\mathrm{G}^{2}=0.14\right.$, d.f. $\left.=1, p=0.70\right)$. Similarly, GM dichotomized by $\mathrm{G} 1 \mathrm{~m}(2)$ did not appear to be related to Type 1 diabetes: $\mathrm{G} 1 \mathrm{~m}(2)$ was positive in $19 \%$ of diabetic and $14 \%$ of control subjects $\left(\mathrm{G}^{2}=0.73\right.$, d.f. $\left.=1, p=0.39\right)$. Finally, GM dichotomized by G3m(5) was not associated

Table 1. GM, KM, and HLA phenotypes: 88 diabetic patients and 64 sibling control subjects

\begin{tabular}{|c|c|c|c|c|c|c|}
\hline \multirow[t]{2}{*}{$\begin{array}{l}\text { HLA-DR } \\
\text { phenotype }\end{array}$} & \multirow[t]{2}{*}{$\begin{array}{l}\text { KM } \\
\text { phenotype }\end{array}$} & \multicolumn{5}{|c|}{$\begin{array}{l}\text { GM phenotype } \\
\text { (probable genotype) }\end{array}$} \\
\hline & & $\begin{array}{l}1 \\
(1 / 1)\end{array}$ & $\begin{array}{l}1,2 \\
(1,2 / 1 \text { or } \\
1,2 / 1,2)\end{array}$ & $\begin{array}{l}1,2,5 \\
(1,2 / 5)\end{array}$ & $\begin{array}{l}1,5 \\
(1 / 5)\end{array}$ & $\begin{array}{l}5 \\
(5 / 5)\end{array}$ \\
\hline
\end{tabular}

\begin{tabular}{lllllrl}
\hline \multicolumn{2}{c}{ Diabetic patients } & & & & & \\
DR3/X & $1-$ & 1 & 2 & 3 & 1 & 5 \\
& $1+$ & 0 & 0 & 0 & 0 & 1 \\
DR3/ & $1-$ & 3 & 1 & 4 & 2 & 8 \\
DR4 & $1+$ & 1 & 0 & 2 & 2 & 2 \\
DR4/X & $1-$ & 0 & 0 & 3 & 11 & 11 \\
& $1+$ & 0 & 0 & 1 & 1 & 5 \\
DRX/X & $1-$ & 0 & 0 & 0 & 1 & 3 \\
& $1+$ & 0 & 0 & 0 & 0 & 0 \\
DR & $1-$ & 0 & 0 & 1 & 4 & 9 \\
unknown $1+$ & 0 & 0 & 0 & 0 & 0 \\
\hline
\end{tabular}

\begin{tabular}{|c|c|c|c|c|c|c|}
\hline \\
\hline \multicolumn{7}{|c|}{$\begin{array}{l}\text { Sibling control subjects } \\
\text { DR3/X } 1-\end{array}$} \\
\hline & $1+$ & 0 & 0 & 0 & 1 & 2 \\
\hline DR3/ & $1-$ & 0 & 1 & 2 & 2 & 1 \\
\hline DR4 & $1+$ & 0 & 0 & 0 & 0 & 0 \\
\hline DR4/X & $1-$ & 2 & 2 & 2 & 6 & 8 \\
\hline & $1+$ & 0 & 0 & 0 & 2 & 2 \\
\hline $\mathrm{DRX} / \mathrm{X}$ & $1-$ & 0 & 0 & 0 & 1 & 4 \\
\hline & $1+$ & 0 & 0 & 1 & 0 & 1 \\
\hline DR & $1-$ & 1 & 0 & 0 & 5 & 4 \\
\hline unknown & $1+$ & 0 & 0 & 0 & 0 & 2 \\
\hline
\end{tabular}

" $D R 3 / X "$ are those positive for DR3 but not DR4. Similarly, "DR4/X" are positive for DR4 but not DR3. "DRX/X" are negative for both DR3 and DR4. Using family data, the numbers of known and possible $3 / 3$ homozygotes among the 13 diabetic DR3/X are 2 $(15 \%)$ and $2(15 \%)$ respectively, while among the 15 control DR3/X they are $3(20 \%)$ and $5(33 \%)$. The numbers of known and possible $4 / 4$ homozygotes among the 32 diabetic DR4/X are $2(6 \%)$ and $10(31 \%)$, while among the 24 control DR4/X they are 0 and $6(25 \%)$ 
with Type 1 diabetes: $91 \%$ of diabetic patients were positive for this antigen compared with $88 \%$ of control subjects $\left(\mathrm{G}^{2}=0.45\right.$, d.f. $\left.=1, p=0.50\right)$. For comparison, approximate frequencies of these immunoglobulin antigens in north-western Europe (Britain, France, Germany) are as follows: $\mathrm{Km}(1), 19 \%$; G1m(1), 50-58\%; G1m(2), 17-23\%, and G3m(5), 88-91\% [21; antigen frequencies calculated from haplotype frequencies, assuming Hardy-Weinberg equilibrium].

\section{Interactions between two genetic markers and disease}

The data were next examined for associations between immunoglobulin marker and disease that were HLADR-dependent - i.e., interaction effects. The analyses were performed on a sample of 70 diabetic and 45 sibling control subjects, since $\mathrm{DRX} / \mathrm{X}$ individuals were not included. With GM dichotomized by $\mathrm{G} 1 \mathrm{~m}(1)$ and HLA classified as DR3/X, DR3/DR4, and DR4/X, there was no interaction effect $\left(\mathrm{G}^{2}=1.29\right.$, d.f. $=2$, $p=0.52$ ). However, with GM dichotomized by G1m(2), there was a possible interaction effect $\left(\mathrm{G}^{2}=5.55\right.$, d.f. $=2, p=0.062$ ). Although the $p$ value was not significant by conventional standards, we felt that, due to the conservativeness of our control subjects (see Subjects), this result could not be ignored. We therefore chose to consider it as 'borderline' significance by modifying our nominal significance level to $\alpha=0.06$. With GM dichotomized by $\mathrm{G} 3 \mathrm{~m}(5)$ there was a significant interaction $\left(\mathrm{G}^{2}=6.91\right.$, d.f. $\left.=2, p=0.031\right)$. Finally, there was no interaction between KM, HLA and Type 1 diabetes, although the $p$ value was low $\left(\mathrm{G}^{2}=4.23\right.$, d. f. $\left.=2, p=0.12\right)$. Thus, two of the four results were significant at the $\alpha=0.06$ level. We determined that correction for multiple tests was unnecessary (see Appendix), and therefore proceeded to examine these two interactions in greater detail.

The interaction of G1m(2) and HLA-DR appears to be related to DR3 in the absence of DR4. Table 2 shows

Table 2. Relationship between GM dichotomized by G1m(2) and HLA in 70 diabetic patients and 45 sibling control subjects

\begin{tabular}{|c|c|c|c|c|c|}
\hline \multirow{3}{*}{$\begin{array}{l}\text { HLA } \\
\text { phenotype }\end{array}$} & \multicolumn{5}{|c|}{ G1m(2) positive/total } \\
\hline & \multicolumn{2}{|c|}{ Diabetic patients } & \multicolumn{3}{|c|}{ Control subjects } \\
\hline & No. & $\%$ & No. & $\%$ & \\
\hline $\mathrm{DR} 3 / \mathrm{X}$ & $5 / 13$ & 39 & $1 / 15$ & 7 & \\
\hline DR3/DR4 & $7 / 25$ & $11 / 57(19)$ & $3 / 6$ & 50 & $7 / 30(23)$ \\
\hline $\mathrm{DR} 4 / \mathrm{X}$ & $4 / 32$ & $11 / 57(19)$ & $4 / 24$ & 17 & $7 / 30(23)$ \\
\hline
\end{tabular}

Table 3. Relationship between GM dichotomized by G3m(5) and HLA in 70 diabetic patients and 45 sibling control subjects

\begin{tabular}{|c|c|c|c|c|c|c|}
\hline \multirow{3}{*}{$\begin{array}{l}\text { HLA } \\
\text { phenotype }\end{array}$} & \multicolumn{6}{|c|}{$\mathrm{G} 3 \mathrm{~m}(5)$ positive/total } \\
\hline & \multicolumn{3}{|c|}{ Diabetic patients } & \multicolumn{3}{|c|}{ Control subjects } \\
\hline & No. & $\%$ & & No. & $\%$ & \\
\hline $\begin{array}{l}\mathrm{DR} 3 / \mathrm{X} \\
\mathrm{DR} 3 / \mathrm{DR} 4\end{array}$ & $\begin{array}{l}10 / 13 \\
20 / 25\end{array}$ & $\begin{array}{l}77 \\
80\end{array}$ & $30 / 38(79)$ & $\begin{array}{c}13 / 15 \\
5 / 6\end{array}$ & $\begin{array}{l}87 \\
83\end{array}$ & $18 / 21(86)$ \\
\hline $\mathrm{DR} 4 / \mathrm{X}$ & $32 / 32$ & 100 & & $20 / 24$ & 83 & \\
\hline
\end{tabular}

that G1m(2) was increased in diabetic patients who had DR3 but did not have DR4. While $39 \%$ of DR3/X patients were positive for $\mathrm{G} 1 \mathrm{~m}(2)$, only $7 \%$ of $\mathrm{DR} 3 / \mathrm{X}$ sibling controls were positive for that antigen $\left(\chi^{2}=4.18\right.$, d.f. $=1, p=0.041$; Fisher's exact test, $p=0.069$ ). On the other hand, the frequency of $\mathrm{G} 1 \mathrm{~m}(2)$ in diabetic patients who had DR4 (19\%) was about the same as in controls who had DR4 $\left(23 \% ; \chi^{2}=0.20\right.$, d.f. $\left.=1, p=0.65\right)$. When HLA was dichotomized as DR3/X versus non$\mathrm{DR} 3 / \mathrm{X}$, and GM dichotomized by G1m(2), the GMHLA-Type 1 diabetes interaction was significant $\left(\mathrm{G}^{2}=4.15\right.$, d. $\left.\mathrm{f} .=1, p=0.042\right)$.

The interaction of G3m(5) and HLA-DR appears to be related to DR4 in the absence of DR3. Table 3 shows that $\mathrm{G} 3 \mathrm{~m}(5)$ was increased in diabetic patients who had DR4 but did not have DR3. While $100 \%$ of DR4/X patients were positive for $\mathrm{G} 3 \mathrm{~m}(5)$, only $83 \%$ of DR4/X controls were positive for that antigen $\left(\chi^{2}=5.74\right.$, d.f. $=1, p=0.017)$. On the other hand, the frequency of G3m(5) in DR3 diabetic patients (79\%) was not significantly different from that seen in DR3 controls $(86 \%$; $\chi^{2}=0.41$, d.f. $=1, p=0.53$ ). When HLA was dichotomized as DR4/X versus non-DR4/X, and GM dichotomized by G3m(5), the GM-HLA-Type 1 diabetes interaction was significant $\left(\mathrm{G}^{2}=6.99\right.$, d.f. $\left.=1, p=0.008\right)$.

\section{Discussion}

The results reported here suggest that the GM locus (or a locus in linkage disequilibrium with GM) influences susceptibility to Type 1 diabetes by modifying effects of the HLA-DR locus (or a locus in linkage disequilibrium with HLA-DR). The epistatic interactions can be summarized as follows: (a) possession of $\mathrm{G} 1 \mathrm{~m}(2)$ appears to increase susceptibility in individuals who have DR3 but not DR4; (b) possession of G3m(5) appears to increase susceptibility in individuals who have DR4 but not DR3. The lack of an observable GM effect in individuals who have both DR3 and DR4 could be due to the overwhelming effect of the DR3/DR4 genotype itself on susceptibility.

Three previous studies [22-24] have looked for associations between GM and Type 1 diabetes and found none. Thus, the present study agrees with other reports. A fourth study [25] reported a significantly increased frequency of $\mathrm{G} 1 \mathrm{~m}(2)$ in Japanese Type 1 diabetic patients who produced anti-insulin antibodies (45\%), as compared with the frequency in patients who did not (28\%). These GM differences were related to immune response to exogenous insulin and may not be important in the aetiology of Type 1 diabetes. Alternatively, the GM differences could reflect aetiologically important interactions between GM, HLA and Type 1 diabetes if: (a) a particular HLA antigen were associated with immune response to insulin (it has been suggested that, in Caucasoids, DR4 shows this association [26]), and (b) the same HLA antigen interacted with $\mathrm{G} 1 \mathrm{~m}(2)$ to increase susceptibility to Type 1 diabetes.

Schanfield et al. [27] reported an increased frequency of $\mathrm{Km}(1)$ in Type 1 diabetic patients as compared 
with sibling controls. Although we did not find a direct relationship between KM and Type 1 diabetes, we did find a low $p$ value for KM-HLA-Type 1 diabetes interaction - it is possible that larger samples will reveal significant HLA-dependent KM differences between patients and controls.

Striking evidence for an interaction between GM, HLA, and autoimmune chronic active hepatitis has been reported by Whittingham et al. [28]. They found an increase of $\mathrm{G} 1 \mathrm{~m}(2)$ only among patients who possessed HLA-B8, which in turn was associated with the disease. Since HLA-B8 is in disequilibrium with HLA-DR3, this would seem to be the same interaction we report here for Type 1 diabetes and may be common to many DR3-associated autoimmune disorders in Caucasoids.

Another interaction between GM, HLA, and an autoimmune disorder has been observed by Kagnoff et al. [29] in patients with gluten-sensitive enteropathy: all patients lacking DR3 (which is associated with the disease) were homozygous for the $\mathrm{Gm}^{5}$ haplotype. In the present study, all Type 1 diabetic patients lacking DR3 (including those who were $\mathrm{DRX} / \mathrm{X}$ ) were positive for G3m(5) and thus possessed the $G m^{5}$ haplotype, although not all were homozygous for that haplotype (Table 1).

The finding of an association between a marker and disease susceptibility, or an interaction between two markers and disease susceptibility, does not automatically lead to the conclusion that there are disease susceptibility loci (e.g. immune response genes) linked to the marker loci. Although linkage between a susceptibility locus and a marker locus may produce an association if there is also linkage disequilibrium between the loci (that is, alleles at the susceptibility locus are coupled with marker alleles in a non-random manner), linkage is not proven by the finding of an association since there are other possible causes of association [30, 31]. For example, the marker locus may interact with an unlinked disease susceptibility locus, or the marker locus itself may affect disease susceptibility. Methods for distinguishing between the possible causes of an association are not yet well developed.

Assuming that the known HLA-DR associations with Type 1 diabetes are caused by an HLA-DR-linked susceptibility locus, several investigators have argued that there are two different alleles at this locus which increase susceptibility through different mechanisms, one in linkage disequilibrium with DR3 and the other in disequilibrium with DR4. The argument is based on clinical differences between DR3- and DR4-positive diabetics, and the increased risk of Type 1 diabetes in individuals who are heterozygous for DR3 and DR4 compared with those who are homozygous for either DR3 or DR4 [for reviews and conflicting interpretations, 32, 33]. The results reported here could be considered to support that hypothesis: the $\mathrm{G} 1 \mathrm{~m}(2)$ haplotype interacts with the susceptibility allele in disequilibrium with DR3, and the G3m(5) haplotype interacts with the susceptibility allele in disequilibrium with DR4. However, our results are also compatible with a hypothesis that GM haplotypes (or alleles at a locus in linkage disequilibrium with GM) interact directly with specific HLA-DR alleles, independent of alleles at any HLADR-linked susceptibility locus.

Evidence which may support the existence of more than one locus affecting predisposition to Type 1 diabetes has been reported from two recent linkage studies $[34,35]$. They showed that linkage between the HLA locus and a hypothetical Type 1 diabetes susceptibility locus is tight in families where the proband is a DR3/DR4 heterozygote but loose in families where the proband is not. This has been interpreted to mean that other susceptibility loci (not linked to HLA) are important in families where the proband is not DR3/DR4, and the effects of these other loci simulate recombination between HLA and the HLA-linked diabetes locus. Furthermore, it has been argued [36] that the HLAlinked and HLA-unlinked determinants have interacting rather than independent effects on susceptibility. Our results suggest that GM on chromosome 14 (or a locus linked to GM), interacting with HLA-DR on chromosome 6 (or a locus linked to this), is a strong candidate for a diabetes susceptibility locus which is not linked to HLA. Further studies with carefully chosen controls are now needed to corroborate or refute this interesting possibility.

Acknowledgments. We thank Dr. M. S. Schanfield for generously providing the reagents Wat, Rut, and Hun, and Mrs. C. Sproule for her secretarial assistance. Funded by grant AM-25834 from the National Institutes of Health (USA), and a grant from the Kroc Foundation. Computer funds were provided by the Office of Academic Computing, UCLA, and Computing Services, University of Calgary.

\section{Appendix}

The usual correction for multiple tests is to multiply the nominal probability of Type 1 error, $\alpha$, by the number of tests performed [37]. This correction is appropriate when only one of the $\mathrm{N}$ tests is nominally significant, but not when two or more are significant, as will be shown.

Let $\alpha$ denote the desired probability of Type 1 error for a single test. Thus, $\alpha=$ Prob ["significant" result $\mid \mathrm{H}_{0}$ true], for a single test. Let $\mathrm{N}$ denote the total number of independent tests performed, and let $\mathrm{X}$ denote the number of tests that are nominally significant at the $\alpha$ level.

The corrected $p$ value we seek is denoted $P_{\alpha}(\mathrm{X}$ of $\mathrm{N})$ and equals Prob [at least $\mathrm{X}$ out of $\mathrm{N}$ tests are significant at $\alpha$ level $\mid \mathrm{H}_{0}$ true for all $\mathrm{N}$ analyses]. This can be expressed as a binominal probability:

$P_{\alpha}(\mathrm{X}$ of $\mathrm{N})=\sum_{\mathrm{i}=\mathrm{X}}^{\mathrm{N}}\left(\begin{array}{l}\mathrm{N} \\ \mathrm{i}\end{array}\right) \alpha^{\mathrm{i}}(1-\alpha)^{\mathrm{N}-\mathrm{i}}$

or

$$
=1-\sum_{\mathrm{i}=0}^{\mathrm{X}-1}\left(\begin{array}{l}
\mathrm{N} \\
\mathrm{i}
\end{array}\right) \alpha^{\mathrm{i}}(1-\alpha)^{\mathrm{N}-\mathrm{i}}
$$

Either Eqs. (1) or (2) may be used, whichever is easier to calculate.

We can use the above expressions to assess the need to correct for multiple tests in the present study. Let $\alpha=0.06$ denote our desired probability of type 1 error for a single test (we chose $\alpha=0.06$ rather than $\alpha=0.05$ for reasons given in the text). Let $N=4$, the number of interaction analyses performed (HLA $\times$ each of four immunoglobulin antigens $\times$ disease). Applying Eq. (2), we see that the probability of observing 2 out of 4 tests significant at the $\alpha=0.06$ level, when in fact all the $\mathrm{H}_{0}$ are true, is:

$P_{0.06}(2$ of 4$)=1-\sum_{\mathrm{i}=0}^{1}\left(\begin{array}{l}4 \\ \mathrm{i}\end{array}\right)(0.06)^{\mathrm{i}}(0.94)^{4-\mathrm{i}}=0.020$ 
Since the probability of type 1 error for the four tests $(0.020)$ is not greater than the desired nominal level $(0.06)$, we conclude that no correction is needed for the effect of multiple tests.

Note that when $\mathrm{X}=1$, Eq. (2) becomes $P_{\alpha}(1$ of $\mathrm{N})=1-(1-\alpha)^{\mathrm{N}}$, which is approximately equal to $\mathrm{N} \alpha$ for small $\alpha$. This represents the usual correction for multiple tests.

\section{References}

1. Cahill GF, McDevitt HO (1981) Insulin-dependent diabetes mellitus: the initial lesion. N Engl J Med 304: 1454-1465

2. Katz DH (1977) Lymphocyte differentiation, recognition and regulation. Academic Press, New York, pp 536-538

3. Benacerraf B (1981) Role of MHC gene products in immune regulation. Science 212: 1229-1238

4. Schanfield MS, Wells JV, Fudenberg HH (1979) Immunoglobulin allotypes and response to tetanus toxoid in Papua, New Guinea. J Immunogenet 6: 311-315

5. Sasazuki T, Kohno Y, Iwamoto I, Tanimura M, Naito S (1978) Association between an HLA haplotype and low responsiveness to tetanus toxoid in man. Nature 272:359-361

6. Whittingham S, Mathews JD, Schanfield MS, Tait BD, Mackay IR (1980) Interactive effect of Gm allotypes and HLA-B locus antigens on the human antibody response to a bacterial antigen. Clin Exp Immunol 40: 8-15

7. Pandey JP, Fudenberg HH, Virella G, Kyong CU, Loadholt CB, Galbraith RM (1979) Association between immunoglobulin allotypes and immune responses to $\mathrm{H}$. Influenza and meningococcus polysaccharides. Lancet 1: 190-192

8. Pandey JP, Zollinger W, Fudenberg HH, Loadholt CB (1981) Immunoglobulin allotypes and immune response to meningococcal group B polysaccharides. J Clin Invest 68: 1378-1380

9. Svejgaard A, Platz P, Ryder LP(1980) Joint report: insulin-dependent diabetes mellitus. In: Terasaki PI (ed) Histocompatibility Testing 1980, UCLA Tissue Typing Laboratory, Los Angeles, pp 638-656

10. Anderson CE, Hodge SE, Rubin R, Rotter JI, Terasaki PI, Irvine WJ, Rimoin DL (1983) A search for heterogeneity in insulin-dependent diabetes mellitus: HLA and autoimmune studies in simplex, multiplex, and multigenerational families. Metabolism 32: $471-477$

11. Hodge SE, Anderson CE, Neiswanger K, Sparkes RS, Rimoin DL (1983) The search for heterogeneity in insulin-dependent diabetes mellitus (IDDM): linkage studies, two-locus models, and genetic heterogeneity. Am J Hum Genet 35: 1139-1155

12. Hodge SE, Anderson CE, Neiswanger K, Field LL, Spence MA, Sparkes RS, Sparkes MC, Crist M, Terasaki PI, Rimoin DL, Rotter JI (1981) Close genetic linkage between diabetes mellitus and Kidd blood group. Lancet 2: 893-895

13. Rotter JI, Anderson CE, Rubin R, Congleton JE, Terasaki PI, Rimoin DL (1983) HLA genotypic study of insulin dependent diabetes. The excess of DR3/DR4 heterozygotes allows rejection of the recessive hypothesis. Diabetes 32:169-174

14. Steinberg AG (1962) Progress in the study of genetically determined human gamma-globulin types (the $\mathrm{Gm}$ and Inv groups). Prog Med Genet II: 1-33

15. Terasaki PI, Bernoco D, Park MS, Ozturk G, Iwaki Y (1978) Microdroplet testing for HLA-A, $-\mathrm{B},-\mathrm{C}$ and $-\mathrm{D}$ antigens. Am $\mathbf{J}$ Clin Pathol 69: 103-120

16. Kotze TJN (1982) The log-linear model and its application to multiway contingency tables. In: Hawkins DM (ed) Topics in applied multivariate analysis. Cambridge University Press, Cambridge, pp 142-182

17. Brown MB (1981) Frequency tables-P4F. In: Dixon WJ (ed) BMDP statistical software 1981, University of California Press, Berkeley, pp 143-206

18. Brown MB (1976) Screening effects in multidimensional contingency tables. Appl Statist 25: 37-46

19. Starmer CF, Grizzle JE, Sen PK (1974) Comment re: Fisher's exact test. J Am Stat Assoc 69: 376-378

20. Baur MP, Danilovs JA (1980) Population analysis of HLA-A, B,
C, DR and other genetic markers. In: Terasaki PI (ed) Histocompatibility testing 1980. UCLA Tissue Typing Laboratory, Los Angeles, $\mathrm{p} 960$

21. Johnson WE, Kohn PH, Steinberg AG (1977) Population genetics of the human allotypes $\mathrm{Gm}$, Inv, and A2m. Clin Immunol Immunopathol 7:97-113

22. Nakao Y, Matsumoto $H$, Miyazaki T, Nishitani $H$, Takatsuki $K$, Kasukawa R, Nakayama S, Izumi S, Fujita T, Tsuji K (1980) IgG heavy chain allotypes $(\mathrm{Gm})$ in autoimmune diseases. Clin Exp Immunol 42: $20-26$

23. Farid NR, Barnard JM, Pepper B, Noel EP, Kelly F, Davis AJ, Hobeika C, Marshall WH (1978) The association of HLA with juvenile diabetes mellitus in Newfoundland. Tissue Antigens 12 : $215-222$

24. Bertrams J, Schoeps L, Baur MP, Luboldt W, van Loghem E (1983) IgG and IgA heavy chain allotypes in Type 1 diabetes. J Immunogenet 10: 305-310

25. Nakao Y, Matsumoto H, Miyazaki T, Mizuno N, Arima N, Wakisaka A, Okimoto K, Akazawa Y, Tsuji K, Fujita T (1981) IgG heavy chain $(\mathrm{Gm})$ allotypes and immune response to insulin in insulin-requiring diabetes mellitus. N Engl J Med 304: 407-409

26. Schernthaner $G$ (1982) The relationship between clinical, immunological and genetic factors in insulin-dependent diabetes. In: Kobberling J, Tattersall R (eds) The genetics of diabetes mellitus. Academic Press, New York, pp 99-115

27. Schanfield MS, Brown R, Sarjeantson S, Kirk RL (1981) Susceptibility to juvenile onset diabetes in families: $\mathrm{DR}, \mathrm{Gm}, \mathrm{Km}$ and gender. Am J Hum Genet 33: 133A

28. Whittingham S, Mathews JD, Schanfield MS, Tait BD, MacKay IR (1981) Interaction of HLA and Gm in autoimmune chronic active hepatitis. Clin Exp Immunol 43: 80-86

29. Kagnoff MF, Weiss JB, Brown RJ, Lee T, Schanfield MS (1983) Immunoglobulin allotype markers in gluten-sensitive enteropathy. Lancet 1: 952-953

30. Clerget-Darpoux F, Bonaïti-Pellié C (1980) Epistasis effect: an alternative to the hypothesis of linkage disequilibrium in HLA associated diseases. Ann Hum Genet 44: 195-304

31. Hodge SE, Spence MA (1981) Some epistatic two-locus models of disease II. The confounding of linkage and association. Am J Hum Genet 33: 396-406

32. Rotter JI, Vadheim CM, Raffel LJ, Rimoin DL (1983) Genetics, diabetes mellitus heterogeneity, and coronary heart disease. In: Rao DC (ed) Genetic epidemiology of coronary heart disease. Alan R Liss, New York (in press)

33. Curie-Cohen M, MacDonald MJ (1982) Genetic heterogeneity in juvenile onset insulin-dependent diabetes: a critical review. In Kobberling J, Tattersall R (eds) The genetics of diabetes mellitus. Academic Press, New York, pp 123-136

34. Green A, Morton NE, Iselius L, Svejgaard A, Platz P, Ryder LP, Hauge M (1982) Genetic studies of insulin-dependent diabetes mellitus: segregation and linkage analyses. Tissue Antigens 19: 213-221

35. Dunsworth TS, Rich SS, Morton NE, Barbosa J (1982) Heterogeneity of insulin-dependent diabetes - new evidence. Clin Genet 21: $233-236$

36. Morton NE, Green A, Dunsworth T, Svejgaard A, Barbosa J, Rich SS, Iselius L, Platz P, Ryder LP (1983) Heterozygous expression of insulin-dependent diabetes mellitus determinants in the HLA system. Am J Hum Genet 35: 201-213

37. Svejgaard A, Jersild C, Starrb Neilsen L, Bodmer WF (1974) HLA antigens and disease: statistical and genetical considerations. Tissue Antigens 4: 95-105

Received: 3 April 1984

and in revised form: 19 July 1984

Dr. Leigh Field

Medical Genetics Clinic

Alberta Children's Hospital

1820 Richmond Road SW

Calgary, Alberta

Canada T2T 5C7 